\title{
TITANGOS, Hui-Lan H. Local communities in the era of social media technologies: a global approach. Oxford: Chandos. 2013. 281 pages. ISBN 978184334696 8. £52.50.
}

This title is part of the Chandos Publishing Social Media Series, and as such I was looking forward to reading a volume which would enlighten me as to how local communities are engaged through interactions with social media. I was also very keen to find out what the library's role is within this arena and the book certainly suggests that it would take a "global approach" towards its subject matter.

On reflection, I think that I was judging this book by its cover, along with the little prior information I had about it. As a book about 'social media technologies' it does not really deliver. It is laid out in five distinct parts, and social media is not really discussed until parts four and five, and even then it is not addressed with any particular depth.

However what this book certainly does deliver is something the reader is not really expecting, a unique insight into the history of the Santa Cruz Public Library Service in California. The author uses a very detailed historic case study about Santa Cruz, in order to illustrate the "community" context of public libraries and it is questionable whether this represents the "global approach" which the book's title promises. The author writes very emotively and descriptively about her adopted homeland, that of Santa Cruz county (where she has lived since 1989) and it is clearly a place and a community which she holds in very high regard. The quirky and parochial nature of this context actually makes for a fascinating read and presents quite a different and often subjective approach to "community libraries". This style and approach would not normally be expected from such a title and an academic or researching practitioner audience might be puzzled as to how the book is structured and where the author's often long and colourful narrative is taking them.

With this in mind, I could not help but be charmed by the text and was continuously interested and eager to read about the next chapter in the history of the Santa Cruz Public Library. In particular, the initial chapters of the book introduce us to several very colourful 'real life' characters who have played significant roles in the development of this local library community.

After entertaining the reader with the story of the library's nineteenth century origins and early twentieth century developments, the author then compartmentalises the book into sections about "Library 1.0", "Library 2.0" and ultimately, "Library 3.0" in order to discuss Santa Cruz Public Library's digital developments. This is interspersed with three international case studies to further illustrate these developments and initiatives. These other examples appear to have been randomly selected and are not necessarily joined up with the main substantive case study. They do however add to the rich nature of the content of the book and further add to the charm of it.

The final part of the book begins to discuss and present a few examples of Library 3.0, and chapter seventeen, which is about local needs versus global needs, is the most informative with regard to the book's supposed subject matter. On 
concluding the book readers might just wonder how they actually and eventually got to the end, with its rather unique and peculiar layout and structure. Having said all this, the book is actually fascinating and is a very interesting read, worth persevering with. It may not be quite what you were expecting but you will be all the more knowledgeable about the Santa Cruz Public Library community by the end of it.

\section{Leo Appleton}

Assistant Director of Library Services

Liverpool John Moores University

1.appleton1@ljmu.ac.uk 